\section{CrossMark} \&lick for updates

Cite this: New J. Chem., 2017, 41,212

Received (in Montpellier, France) 26th March 2016 ,

Accepted 12th November 2016

DOI: 10.1039/c6nj00960c

www.rsc.org/njc

\title{
Supramolecular combinations of humic polyanions as potent microbicides with polymodal anti-HIV-activities $\uparrow$
}

\author{
Yury V. Zhernov, ${ }^{a}$ Stephan Kremb, ${ }^{\mathrm{b}}$ Markus Helfer, ${ }^{\mathrm{b}}$ Michael Schindler, ${ }^{\mathrm{c}}$ \\ Mourad Harir, ${ }^{d}$ Constanze Mueller, ${ }^{d}$ Norbert Hertkorn, ${ }^{d}$ Nadezhda P. Avvakumova, \\ Andrey I. Konstantinov, ${ }^{f}$ Ruth Brack-Werner, ${ }^{b}$ Philippe Schmitt-Kopplin ${ }^{d g}$ and \\ Irina V. Perminova ${ }^{\star f}$
}

\begin{abstract}
This article focuses on linking structures of fractionated humic polyanions (PAs), which were molecularly defined using ultrahigh resolution Fourier transform mass spectrometry (FTMS), to their antiviral activities with respect to laboratory HIV-1 strains. Anti-HIV-1 activity was proven using a full HIV-1 replication system validated for antiviral testing. We demonstrated that all humic PAs tested in our study were capable of inhibiting HIV fusion. The most hydrophobic fractions of humic and hymatomelanic PAs also strongly inhibited HIV-1 reverse transcriptase. The structure-activity analysis revealed the direct relationship of antiviral activities with contribution of $\mathrm{CHO}$ molecules in humic PA composition and lipophilicity index, and the inverse relationship with their carboxylic and total acidity. This was explained by the supramolecular character of humic PAs, the properties of which are ruled rather by the contribution of most potent scaffolds than by the total charge density. It is concluded that all humic PAs tested in this study can be considered as promising precursors for developing cost-effective combinatorial microbicides with polymodal anti-HIV activity and low cytotoxicity capable of preventing HIV-1 transmission.
\end{abstract}

\section{Introduction}

HIV infection remains one of the most serious threats to human health. This is despite substantial progress which has been achieved as a result of the advent of highly active antiretroviral

\footnotetext{
${ }^{a}$ State Research Center "Institute of Immunology" of the Federal Medical-Biological Agency of Russia, Moscow, Russia

${ }^{b}$ Institute of Virology, Helmholtz Zentrum München - German Research Center for Environmental Health, Neuherberg, Germany

${ }^{c}$ University Hospital Tübingen, Institute for Medical Virology and Epidemiology of Viral Diseases, Tübingen, Germany

${ }^{d}$ Research Unit Analytical BioGeoChemistry, Helmholtz Zentrum München - German Research Center for Environmental Health, Neuherberg, Germany

${ }^{e}$ Samara State Medical University, Department of General, Bioinorganic and Bioorganic Chemistry, Samara, Russia

${ }^{f}$ Lomonosov Moscow State University, Department of Chemistry, Moscow, Russia. E-mail: iperm@med.chem.msu.ru

${ }^{g}$ Technical University of Munich, Division of Analytical Food Chemistry, Freising-Weihenstephan, Germany

$\dagger$ Electronic supplementary information (ESI) available: Isolation scheme of humic PAs, RPLC profiles, ${ }^{13} \mathrm{C}$ NMR spectra, dose-response relationship profiles for antiviral properties, cytotoxicity curves for the humic PAs under study, Van Krevelen diagrams for different classes of antiretroviral compounds positioned along the HIV-life cycle, and the corresponding tabular data. See DOI: 10.1039/ c6nj00960c
}

therapy (HAART) ${ }^{1,2}$ Twenty six single-molecule drugs and eleven fixed-dose combination drugs have been approved for use in antiHIV-1 therapies by the U.S. FDA, ${ }^{3}$ and many more experimental drugs are under way. However, because of the problem of drug resistance, these single-molecule drugs are almost never used as a mono-therapy, instead, combinations of two to four drugs are required. ${ }^{4}$ The negative pay-off of such an approach, which increases the success of HAART, is manifold magnification in cellular toxicity, multiple drug resistance, and other adverse sideeffects of the corresponding treatment. ${ }^{5}$ Hence, alternative HIV treatments are in high demand. ${ }^{1}$

Among these alternatives is the use of polyanionic (PA) microbicides developed as effective HIV entry inhibitors capable of blocking virus adsorption to the surface of the host cell membrane $\left(\mathrm{CD}^{+}\right) .{ }^{6,7}$ This occurs through electrostatic interactions of negatively charged polyanions with the positively charged V3 loop of the HIV-1 glycoprotein 120 (gp120) or the glycoprotein 41 (gp41) complex. ${ }^{7-11}$ PA microbicides are mostly presented by sulfonated or sulfated polymers which show high anti-HIV activity in vitro at very low concentrations. ${ }^{9,10}$ However, some sulfonated PAs indicated the potential enhancement of the infection rate after washout of microbicides. ${ }^{12-14}$ The infection was caused by the disruption of the integrity of the mucosal epithelial surface induced by the surface activity of some sulfonated or 
sulfated PAs (e.g. cellulose sulfate, Carraguard, PRO-2000), which might have enabled HIV-1 spread across the epithelium. ${ }^{15,16}$ Fortunately, this effect was not reported after washout of carboxylated PAs, ${ }^{17}$ which possess less surface charge and surface activity as compared to the sulfonated molecules, and will be considered in more detail below.

The carboxylated PAs, which showed high anti-HIV activity, include aurintricarboxylic acid, ${ }^{18}$ carboxylated dextrins, ${ }^{7}$ polymerized carboxylated surfactants, ${ }^{19}$ phthalate- and trimellitatederivatized celluloses, ${ }^{20-22}$ cosalane derivatives with extended polycarboxylate pharmacophores, ${ }^{23}$ semi-rigid hybrid copolymers (e.g. poly(styrene-alt-maleic acid), poly(stylbene-alt-maleic acid)), ${ }^{24,25}$ and dendrimers. ${ }^{26}$ Also of particular interest are polymers and dendrimers carrying both carboxylate and sulfate groups. $^{26,27}$ An additional advantage of these polyfunctional PAs is a broader spectrum of activities including other sexually transmitted pathogens such as HSV-2, ${ }^{7,17,27} \mathrm{HPV},{ }^{28}$ and Neisseria gonorrhoeae. $^{29}$ Thus, they may be suitable ingredients for multipurpose prevention products. Still, controllable synthesis of polymers and dendrimers with tailored anti-HIV properties remains a laborious multi-step procedure.

In this respect, natural carboxylated PAs - humic substances (HSs) - deserve particular attention. HSs are the products of abiotic combinatorial synthesis yielding the supramolecular assembly of molecules with varying amounts of carboxylic and phenolic units. ${ }^{30}$ The difference in protolytic properties is used for their fractionation. The most acidic fraction enriched with carboxylic groups and soluble at acidic $\mathrm{pH}$ is called fulvic acid (FA), whereas the less acidic fraction enriched with phenolic groups and not soluble at acidic $\mathrm{pH}$ is called humic acid (HA). ${ }^{31}$ Humic acid, in turn, can be fractionated into a more polar fraction - hymatomelanic acids (HMA) soluble in ethanol. Hence, tailoring humic PAs with tunable properties can be performed using fractionation only without a need for chemical modification, which is a substantial advantage over the synthetic PAs.

Indeed, it is reported that the different fractions of natural HSs (as well as those of synthetic HS-like materials) exhibit high anti-HIV activity along with low cytotoxicity. ${ }^{32-35}$ They are also active against influenza virus A/WSN/1933 (H1N1), ${ }^{36}$ HSV-1, ${ }^{37}$ and Coxsackie virus $\mathrm{A} 9,{ }^{38}$ which is consistent with a broad spectrum of antiviral activities reported for synthetic polyanionic microbicides. ${ }^{9,39}$ Moreover, unlike synthetic PAs, they are active both towards enveloped and non-enveloped viruses, which makes their potential range of applications even broader. Despite these numerous findings, systematic studies on HS fractions from a drug-design perspective are very scarce. ${ }^{40}$ This is because, until recently, the arsenal of chemists was lacking the tools required for the identification of molecular compositions of complex supramolecular systems. This situation has changed with the advent of Fourier transform ion cyclotron resonance mass spectrometry (FTICR MS) which has an unprecedented resolution capacity. ${ }^{41,42}$ As a result, it has become the method of choice in resolving the full molecular composition of natural and synthetic HSs. ${ }^{43-46}$ This enables comparative analysis of HS samples and fractions at the molecular level. Still, there have been no data reported on exploring the relationships between molecular compositions and anti-HIV activities of HSs.

Here, we used the fractionation approach to obtain three humic PAs with different structural and protolytic properties and ran advanced instrumental analysis to define the structural scaffolds dominating each fraction. We tested the anti-HIV activity of these humic PAs for two viral strains and explored how the molecular characteristics of the humic PAs affect their microbicidal properties. We have used three criteria: (a) a number of $\mathrm{CHO}$ compositions versus heteroatom-containing compositions (CHON, CHOS, and CHNOS), (b) the overall number of acidic groups per $\mathrm{g}$, and (c) the lipophilicity index. We have also mapped the molecular space of the humic PAs with respect to their entry inhibition and reverse-transcriptase activities using Van Krevelen diagrams, which represent relationships of $\mathrm{H} / \mathrm{C}$ versus $\mathrm{O} / \mathrm{C}$ atomic ratios calculated from the stoichiometric formula of an organic compound. Van Krevelen diagrams are widely used to visualize the molecular space occupied by the components of the complex systems identified with the use of data rich FTICR MS. ${ }^{42-45}$ We believe that molecular recognition of the subspaces of humic systems responsible for a certain type of antiretroviral activity might advance the design of innovative supramolecular microbicides using fractionation of natural supramolecular systems with polymodal anti-HIV activities.

\section{Results}

\section{Molecular characteristics of the humic PAs used in this study}

The source of all humic PAs used in this study was silt sulphide mud with a long history of use for balneological and medicinal purposes. ${ }^{47,48}$ The humic PAs were obtained by fractionation of the total humic extract (HFA) into an acid-insoluble humic acid (HA) fraction, an acid-soluble fulvic acid (FA) fraction, and ethanol-soluble hymatomelanic acid (HMA). Elemental compositions, $\mathrm{p} K_{\mathrm{a}}$, the amount of acidic groups $(\alpha)$, and the lipophlicity index (LI) are shown in Table 1.

The fractionated humic PAs differed substantially in elemental compositions: HMA contained much more carbon (almost 60\%) compared to HA $(52.7 \%)$ and FA (31.2\%). In contrast, FA contained much more oxygen (55\%) and sulfur (5.8\%) versus HMA and HA. This is indicative of the much more oxidized nature of FA compared to HMA and HA. The obtained trends are consistent with the source of humic materials used in this study - sulfide mud rich in sulfur - as well as with the fractionation approach, and corroborate well the reported values for the fractionated $\mathrm{HS}^{49}$ It should be noted here that elemental analyses of HSs isolated from the same source using the same isolation and fractionation techniques yield reproducible values, which are often used for the classification of HSs. $^{49}$

According to the data of potentiometric titrations, FA was characterized with much higher total acidity values (TA) (8.5 mmol g ${ }^{-1}$ ) compared to HA $\left(7 \mathrm{mmol} \mathrm{g}^{-1}\right)$, and HMA $\left(5.5 \mathrm{mmol} \mathrm{g}^{-1}\right)$. Similar trends in acidic group contents in the fractionated HS were reported by Perdue et al. ${ }^{50}$ This enables a conclusion regarding the much higher charge density of fulvic 
Table 1 Elemental and functional characteristics of the humic PAs used in this study

\begin{tabular}{|c|c|c|c|c|c|c|c|c|c|c|c|c|}
\hline Humic PA & \multicolumn{5}{|c|}{ Content of elements, $\%$ mass } & \multicolumn{2}{|c|}{ Atomic ratios } & \multicolumn{4}{|c|}{$\mathrm{p} K$ and content of acidic groups $(\alpha), \mathrm{mmol} \mathrm{g}^{-1}$} & $\frac{\text { LI index }}{\text { LI }}$ \\
\hline FA & 31.2 & 5.9 & 55.03 & 2.1 & 5.77 & 2.3 & 1.32 & 5.2 & 4 & 8.5 & 4.5 & 0.11 \\
\hline HMA & 59.73 & 5.37 & 30.36 & 2.14 & 2.4 & 1.1 & 0.38 & 5.6 & 2 & 9.0 & 3.5 & 0.53 \\
\hline HFA & 56.46 & 6.18 & 33.56 & 2.6 & 1.2 & 1.3 & 0.42 & $\mathrm{n} / \mathrm{d}$ & $\mathrm{n} / \mathrm{d}$ & $\mathrm{n} / \mathrm{d}$ & $\mathrm{n} / \mathrm{d}$ & 0.63 \\
\hline
\end{tabular}

${ }^{a}$ Lipophilicity index (LI) is the content of hydrophobic fractions as determined by RPLC. The detailed explanations are given in the ESI (Fig. S2 and related text).

acid PAs compared to those of HA and HMA, and indicates that $\mathrm{pH}$ might be a strong regulator for manipulating the charge of humic PAs. According to the RPLC data, FA was characterized with the greatest contribution of hydrophilic components comprising $89 \%$ of the molecular compartments of this sample, which is consistent with the data of elemental and functional analyses. In contrast, HA was characterized with the maximum percentage $(74 \%)$ of hydrophobic molecules, whereas for HMA the contribution of hydrophilic and hydrophobic fractions was almost equal. Hence, HA is the most lipophilic compound among all the PAs studied, HMA - amphiphilic and FA - hydrophilic. The data of ${ }^{13} \mathrm{C}$ NMR spectroscopy (Fig. S3, ESI $\dagger$ ) also conformed this trend and demonstrated the largest content of hydrophobic aromatic moieties in HA, whereas HMA has almost equal contributions of aromatic and aliphatic carbon, and FA has the highest contribution of $\mathrm{O}, \mathrm{N}$-substituted aliphatic carbon. The obtained trend in lipophilicity of the fractionated HS is consistent with the literature published for similar investigations using RPLC as well as ${ }^{13} \mathrm{C}$ NMR spectroscopy. ${ }^{51,52}$

To determine specific molecular features of the humic PAs under study, we used FTICR MS measurements. The corresponding Kendrick Mass Defect (KMD) diagrams and Van Krevelen plots (the latter represent relationships of $\mathrm{H} / \mathrm{C}$ versus $\mathrm{O} / \mathrm{C}$ atomic ratios; they are widely used for the interpretation of FTICR MS data on HS) ${ }^{53}$ are shown in Fig. 1A (right and left panels, respectively). We used color encoding to highlight molecules with different atomic compositions (CHO, CHON, CHONS, and CHOS). The amount of assigned formulas of each type for the four humic materials used is shown in Fig. 1B.

The obtained FTICR MS data revealed the high complexity of supramolecular ensembles of the humic PAs used in this study. Still, clear relationships could be seen between the isolation protocol and the molecular compositions of the humic PAs. The largest difference was observed for HMA and FA. The HMA was characterized by a densely populated area of saturated hydrocarbons with $\mathrm{H} / \mathrm{C}>1.2$ and of condensed aromatics with $\mathrm{H} / \mathrm{C}<0.6$. From the KMD plots it can be concluded that HMA is characterized by the highest content of $\mathrm{CH}_{2}$-homologs of lipidic and terpenoidic nature. FA, in turn, is characterized by an extremely high content of heteroatoms. A lot of sulfurcontaining constituents are located in the upper right corner of the Van Krevelen diagram indicating their oxidized character. HFA and HA are characterized by the largest amount of aromatic lignin-like and polyphenolic components (e.g. flavonoids and hydrolyzable tannins) located in the region of $\mathrm{H} / \mathrm{C}$ values from 0.6 to 1.2 , and $\mathrm{O} / \mathrm{C}$ values from 0.5 to 0.8 . In the case of HMA, the KMD diagrams of HA indicate the clear presence of $\mathrm{CH}_{2}$ homological hydrocarbons, which can be seen as parallel series of dots in the bottom region of the diagram, along with the diagonal series of dots produced by polyphenolic compounds, which do not produce homological $\mathrm{CH}_{2}$ series.

The presence of extended $\mathrm{CH}_{2}$ series in HMA is consistent with the high contribution of alkylic fragments observed in the ${ }^{13} \mathrm{C}$ NMR spectra (Fig. S2, ESI $\dagger$ ). It can be related to the substantial content of $\mathrm{CH}_{2}$-chains as well as to the $\mathrm{CH}_{2} \mathrm{O}$ fragments constituting $\mathrm{CH}_{2} \mathrm{O}$-bridges and heterocyclic rings (e.g. furofurans, tetrahydrofurans, and pyrans) in lipids, terpenoids, lignans, etc. present in the molecular composition of HMA. This might be expected given that ethanol/methanol extraction is a common way of isolating these polar components from plant biomass. ${ }^{54}$

To generate quantitative parameters from the molecular compositions obtained, which would be suitable for deriving structure-activity relationships (SARs), we have calculated the amount of molecular constituents composed of CHO, CHON, CHONS, and CHOS atoms, which were found in each fraction of humic PAs, as shown in Fig. 1B.

From the given data it can be concluded that HMA has the most substantial contribution of $\mathrm{CHO}$ components (about $70 \%$ ), whereas FA is characterized by the highest contribution of $\mathrm{N}$ and S containing molecules $(>60 \%)$. HA and HFA have intermediate values. The obtained FTICR MS data are consistent with the results of elemental analysis, which showed the maximum enrichment of FA with heteroatoms other than oxygen ( $\mathrm{N}$ and $\mathrm{S}$ ), whereas their lowest contribution was observed for the elemental composition of HMA. They also corroborate well the data of ${ }^{13} \mathrm{C}$ NMR spectroscopy, which indicate a high contribution of aliphatic and alicyclic compartments (e.g. lipids, terpenoids, and lignans) to the composition of the HMA fraction, whereas the highly aromatic HA fraction might be dominated by polyphenolic acids including hydrolyzable tannins, flavonoids, as well as N-heterocyclic compounds. The FA fraction has the highest contribution of highly oxidized saturated compartments.

\section{Antiviral activity and cytotoxicity of the humic PAs}

Anti-HIV-1 activities of the humic PAs were evaluated using the EASY-HIT assay ${ }^{55}$ and a viral replication assay utilizing primary human cells (human peripheral blood mononuclear cells; PBMCs). The specific feature of the EASY-HIT assay consists of measuring infection parameters associated with two temporally 


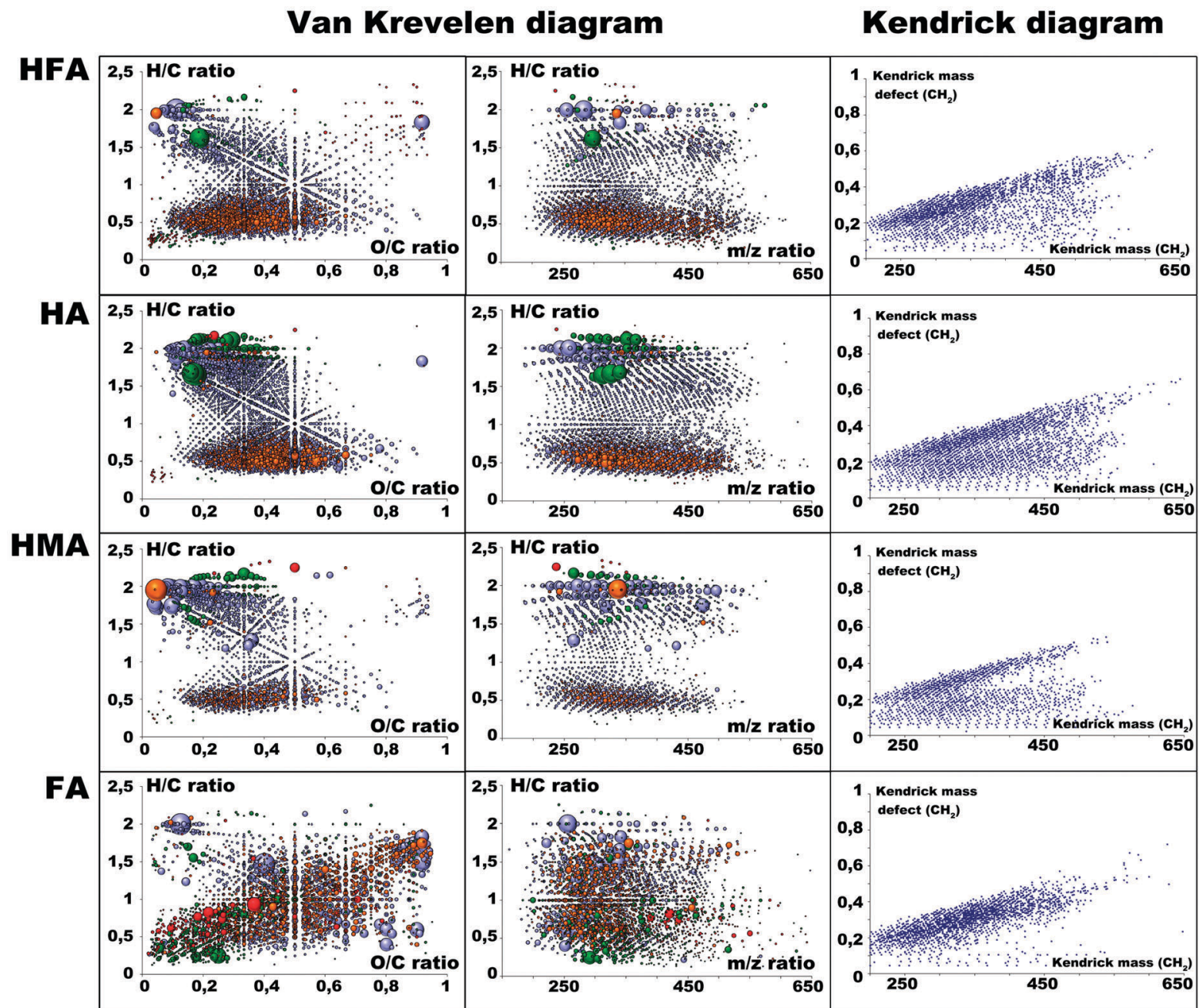

(B)

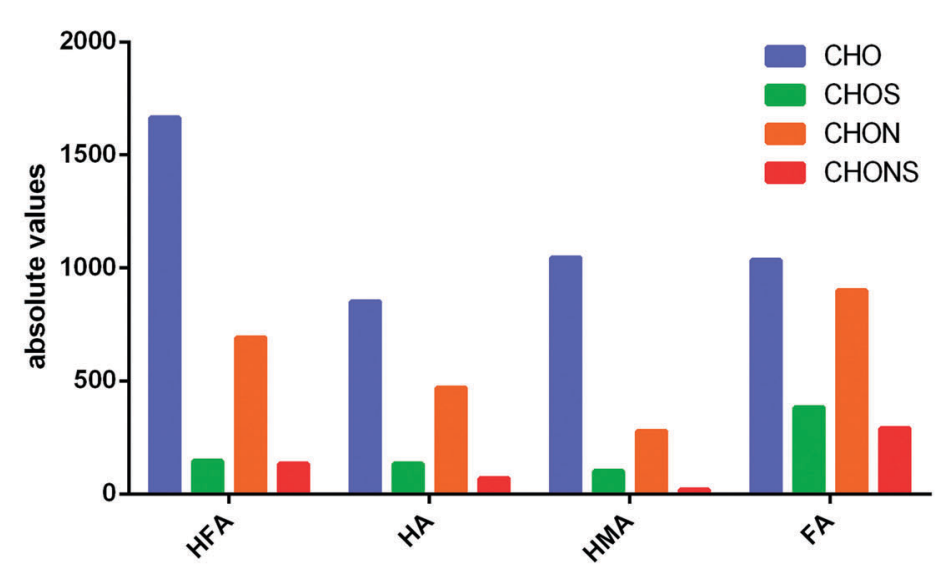

Fig. 1 Van Krevelen diagram (left panel), H/C versus $\mathrm{m} / \mathrm{z}$ ratio (middle panel), and Kendrick Mass Defect (KMD) plots (right panel) (A) and the total amount of different molecular compositions (B) for the four humic PAs used in this study: HFA, HA, HMA, and FA. The dot and column colors denote different atomic compositions: blue ( $\mathrm{CHO})$, orange $(\mathrm{CHON})$, green $(\mathrm{CHOS})$, and red $(\mathrm{CHNOS})$; the dot size is proportional to peak intensity in the mass spectra.

distinct steps of the HIV-1 replication cycle: early events in the HIV-1 replication cycle (step 1), and release of infectious virions (step 2) with an HIV-1 reporter cell line (LC5-RIC). To validate the results obtained using the standard EASY-HIT assay, all humic PAs were also tested for activity on the infection of PBMCs. The quantitative parameters of all the antiviral tests are summarized in Table 2. The corresponding dose-response curves are shown in Fig. S3 in the ESI. $\dagger$

The humic PAs under study showed excellent antiviral activities, which are equal to or higher than those reported for the synthetic carboxylated polymers. ${ }^{56}$ So, the $\mathrm{EC}_{50}$ values determined for both steps of the EASY-HIT assay for HMA and 
Table 2 Assays of antiviral activity and cytotoxicity of the humic PAs used in this study

\begin{tabular}{|c|c|c|c|c|c|}
\hline \multirow{2}{*}{$\begin{array}{l}\text { Humic } \\
\text { PAs }\end{array}$} & \multicolumn{2}{|c|}{$\begin{array}{l}\mathrm{EC}_{50}, \mu \mathrm{g} \mathrm{mL}^{-1} \\
\text { easy-HIT }\end{array}$} & \multirow{2}{*}{$\frac{\mathrm{EC}_{50}, \mu \mathrm{g} \mathrm{mL}^{-1}}{\mathrm{PBMC}}$} & \multirow{2}{*}{$\begin{array}{l}\mathrm{CC}_{50} \\
\mu \mathrm{g} \mathrm{mL}\end{array}$} & \multirow{2}{*}{$\begin{array}{l}\begin{array}{l}\text { Selectivity } \\
\text { index }^{a}\end{array} \\
\text { PBMC }\end{array}$} \\
\hline & Step 1 & Step 2 & & & \\
\hline HMA & 0.038 & 0.044 & 0.98 & $>200$ & $>200$ \\
\hline HA & 0.072 & 0.086 & 2.4 & $>200$ & $>80$ \\
\hline FA & 0.446 & 0.455 & 6.7 & 50 & 7.5 \\
\hline HFA & 0.304 & 0.344 & 2.67 & $>200$ & $>75$ \\
\hline
\end{tabular}

${ }^{a}$ Selectivity index (SI) is calculated as a ratio of the $\mathrm{CC}_{50}$ value (cytotoxicity)/EC $\mathrm{EC}_{50}$ value, where $\mathrm{CC}_{50}$ (cytotoxicity) was $>200$ for HMA, $\mathrm{HA}$, and HFA, and equal to 50 for FA.

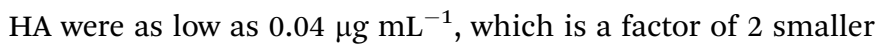
than those determined for carboxylated PAs. For the PBMC tests, the $\mathrm{EC}_{50}$ values determined for HMA $\left(0.98 \mu \mathrm{g} \mathrm{mL}^{-1}\right)$ were at the level of the best values determined for carboxylated PAs (0.76-0.97).

The obtained results indicate that all humic PAs interfered with the early stage of the HIV-1 replication cycle. ${ }^{55}$ Of importance is that the antiviral activities of all humic PAs were consistent among the different assays: the most potent was HMA and the least potent was FA. All humic PAs displayed very low cytotoxicity. The $\mathrm{CC}_{50}$ value of $55 \mu \mathrm{g} \mathrm{mL}^{-1}$ was reached only with FA for the PBMC cells, whereas for all other humic Pas, $\mathrm{CC}_{50}$ was not reached in the full range of concentrations used. The corresponding toxicity curves are shown in the ESI $\dagger$ (Fig. S5). As a result, the $\mathrm{CC}_{50}$ values for HA, HMA, and HFA were estimated based on the largest concentration tested as $>200 \mu \mathrm{g} \mathrm{mL} \mathrm{m}^{-1}$. This value was used for estimating the selectivity index for all humic PAs (except for FA) given in Table 2.

\section{Mechanistic studies for targeting the mode of action of the humic PAs}

Time of addition assay. To obtain insight into the mode of action of humic PAs, a time of addition assay was conducted using the fusion inhibitor $\mathrm{T}-20,{ }^{56}$ the reverse transcription inhibitor AZT, and the integrase inhibitor Raltegravir (RAL) as the reference drugs. This assay was used to indicate a possible target for the humic PAs by deducing it from comparison of time profiles of antiviral activities of the humic PAs with those of T20, AZT, and RAL, as shown in Fig. 2.

Substantial differences can be seen between the mode of action of the humic PAs studied with respect to fusion inhibition and RTI activity: HA, HMA, and HFA lost $50 \%$ of their efficacy at 7-8 h.p.i., which is very close to AZT $(7.7 \pm 0.2)$, whereas the FA profile was similar to that of T20 with a $50 \%$ loss of efficacy reached even at $(5.0 \pm 0.3)$ h.p.i. At the same time, the humic PAs did not show integrase inhibitory activity in the full range of concentrations studied. The observed differences might be indicative of the different mode of action of the fractionated humic PAs which opens a way for tuning their properties as antiviral drugs.

To explore this in more detail, we have conducted HIV-1-cell attachment and reverse transcriptase inhibition (RTI) assays with all humic PAs under study. The corresponding results are

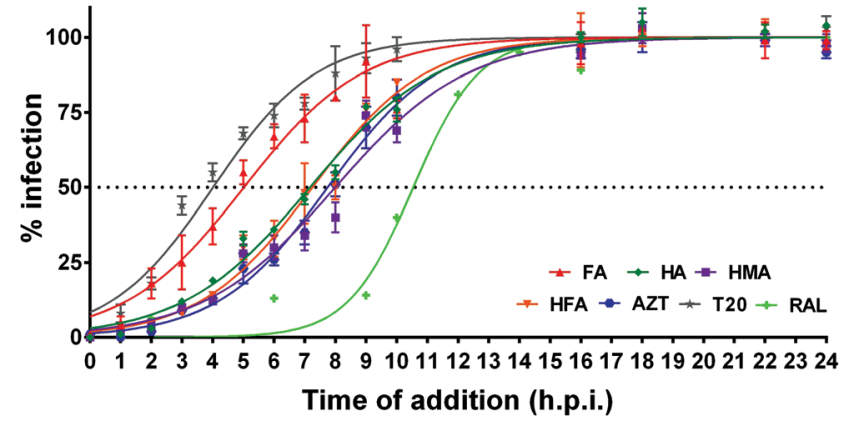

Fig. 2 Time-of-addition profiles obtained for the four humic PAs under study, fusion inhibitor T20, and reverse transcription inhibitor AZT ( $n=3$; $R^{2}>0.9$ ): FA (red triangles), HA (green circles), HMA (violet quadrants), HFA (orange triangles), AZT (blue circles), T20 (grey stars), and RAL (green diamonds).

given in Fig. 3A and B, respectively. Attachment inhibition was performed in the presence of T20 to promote accumulation of HIV at the cell surface and to boost binding to $\mathrm{CD}_{4}$. The negative control (HIV-) consisted of cells without virus inoculum, whereas the positive control (HIV+) included cells exposed to virus particles in the absence of inhibitory compounds.

LC5-RIC-R5 cells were exposed to fluorescently tagged R5 virus particles (R5 HIV-1 NL4-3 Gag-iGFP) in the presence of T20 (fusion inhibitor). The cells were then stained with DAPI (DNA stain; blue). The results show (Fig. 3A) that all humic PAs blocked cellular HIV-1 attachment which is seen as a reduced amount of GFP-spots per cell. Quantitative analysis implied the identification of 160-180 cells from at least 5 images and yielded the following results (in GFR spots per cell): $(8 \pm 4)$ for HIV+, (2.0 \pm 1$)$ for HMA, $(2.3 \pm 0.6)$ for HFA, $(2.3 \pm 0.4)$ for $\mathrm{FA}$, and (2.9 \pm 0.5$)$ for HA. Due to a large measurement error, there was no statistically significant difference seen between HMA, HA and HFA. In general, all humic PAs used in this study can be considered as potent viral entry inhibitors.

Given that three out of four humic PAs in the time of addition assay displayed time profiles similar to AZT, we have screened the RTI activities of all the humic PAs. The obtained data are shown in Fig. 3B. Again, HA, HMA, and HFA inhibited HIV-1 reverse transcriptase in a dose-dependent manner similar to AZT, whereas FA did not have any effect in low concentrations. The obtained values of RTI activities of HMA and HA lie well within the range determined for mixtures of different natural lignans including furofuran-, tetrahydrofuran (THF)-, and neolignans, ${ }^{57-59}$ as well as for polyphenols ${ }^{60,61}$ including flavonoids and hydrolyzable tannins. ${ }^{62}$ This shows that the most hydrophobic humic PAs (HA and HMA) might be considered as new potent non-nucleoside HIV-1 reverse transcriptase inhibitors.

\section{Structure-activity relationships}

To explore the structure-activity relationships for the anti-HIV activities of the humic PAs under study, we have conducted correlation analysis for the set of structural parameters given in Table 1, including amounts of CHO, CHNO, CHSO, and CHNOS assignments, and quantitative indicators of antiviral activities 

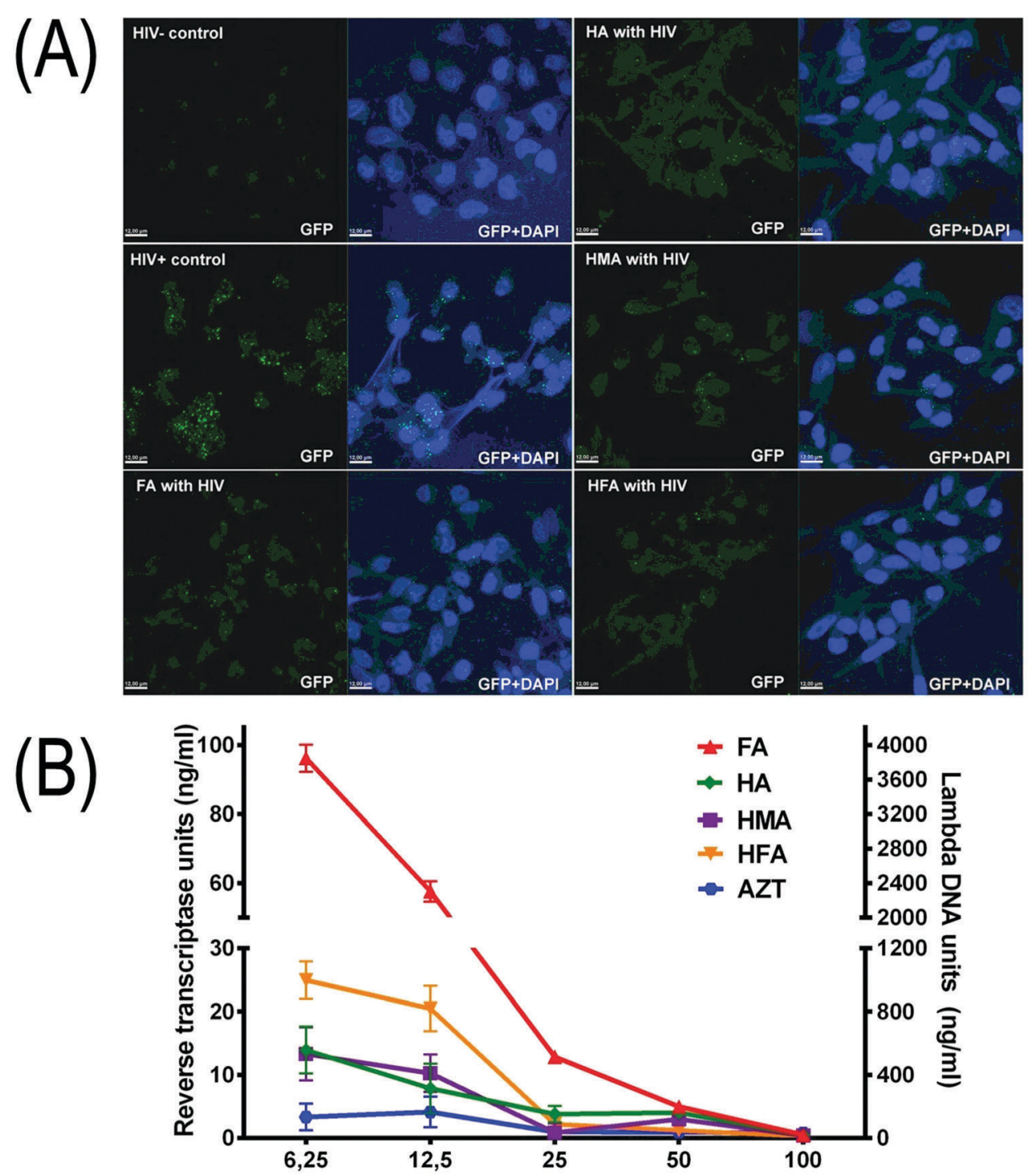

\section{Concentration of $\mathrm{HS}(\mu \mathrm{g} / \mathrm{ml})$ Concentration of AZT (X10 nM)}

Fig. 3 Inhibition of virus attachment to host cells by the humic PAs in the presence of fusion inhibitor T-20 (fluorescence tagged virus particles, R5 HIV-1 NL4-3 Gag-iGFP, green, and LC5-RIC-R5 cells) as determined via fluorescence imaging (A) and reverse transcriptase inhibition activity of the humic PAs (B), which are color-coded as follows: FA (red), HA (green), HMA (violet), and HFA (orange) $\left(n=3 ; R^{2}>0.9\right)$. AZT (the reference) is shown in blue.

$\left(\mathrm{EC}_{50}\right.$ and $\left.\mathrm{CC}_{50}\right)$ determined in the EASY-HIT and PBMC tests (Table 2). The correlation results are given in Table 3.

The results yielded tight inverse relationships for antiviral activities of the humic PAs expressed as $\mathrm{EC}_{50}$ with the contribution of $\mathrm{CHO}$ molecules to their molecular composition with correlation coefficients reaching -0.871 and -0.996 for LC5-RIC and PBMC, respectively. Slightly weaker inverse relationships were observed for the lipophilicity index: $r=-737$ and -0.864 for LC5-RIC and PBMC, respectively. This might be interpreted as an increase in the antiviral properties of humic PAs along with an increase in their hydrophobicity and an increase in the contribution of $\mathrm{CHO}$ compartments to their molecular composition.
On the other hand, the total acidity (a sum of carboxylic and phenolic groups) was directly related to the $\mathrm{EC}_{50}$ values for both cell lines (LC5-RIC and PBMC): the corresponding $r$ values accounted for 0.927 and 0.889 , respectively. Hence, an increase in the charge density on humic PAs was not accompanied by an increase in their antiviral activity. This might be indicative of a more complicated mechanism of humic PA interference with the replication cycle of HIV compared to only electrostatic interactions with the protein loops of the viral capsid. The latter is a leading mode of action of synthetic PAs, the antiviral activity of which increases with the number of charges per molecule. ${ }^{7}$ A lack of such a relationship in the case of humic 
Table 3 Correlation relationships between the structure and the anti-HIV activities of the humic PAs used in this study

\begin{tabular}{|c|c|c|c|c|c|c|c|c|c|}
\hline Anti-HIV activity & \multicolumn{4}{|c|}{ Amount of formula assignments } & \multicolumn{3}{|c|}{ Atomic ratios } & \multicolumn{2}{|c|}{ Total acidity and lipophilicity } \\
\hline $\mathrm{EC}^{2} 0^{a}$ & -0.996 & 0.998 & 0.999 & 0.968 & -0.788 & 0.985 & 0.968 & 0.927 & -0.834 \\
\hline $\mathrm{SI}^{a}$ & 0.827 & -0.845 & -0.875 & -0.726 & 0.969 & -0.946 & -0.780 & -0.991 & 0.471 \\
\hline $\mathrm{EC} 50^{b}$ & -0.871 & 0.895 & 0.867 & 0.829 & -0.669 & 0.902 & 0.935 & 0.889 & -0.737 \\
\hline $\mathrm{SI}^{b}$ & 0.704 & -0.738 & -0.744 & -0.596 & 0.841 & -0.850 & -0.730 & -0.927 & 0.384 \\
\hline
\end{tabular}

PAs might be connected to the substantial difference in the molecular organization of synthetic polymers comprised of homological structural scaffolds with a similar type of activity, from natural humic PAs, the supramolecular assemblies of which are composed of heterogeneous scaffolds carried over from their versatile precursors with different activities. ${ }^{63}$ As a result, a change in the total acidity of the humic PAs is connected to a concomitant change in the prevailing scaffolds within their molecular composition, which might mask the dominant contribution of electrostatic interactions. If they would have dominated, the humic PAs would only be active at the stage of virus adsorption and fusion, which is not the case: the least charged, but the most hydrophobic humic PAs - HMA and HA, inhibit both entry and reverse transcription of viral DNA. Given this multimodal activity of humic PAs, structural descriptors sensitive to molecular compositions of the humic PAs (e.g. amount of $\mathrm{CHO}$ molecules delivered by high resolution FTICR MS) should be preferred over integral constitutive descriptors (e.g. total acidity of humic PAs) for deriving more meaningful SARs.

\section{Discussion}

\section{Tuning structures of humic PAs via fractionation}

Fractionation of natural HSs was performed using a conventional approach based on the acidity and lipophilicity of the humic molecular components. Exhaustive molecular analysis of the obtained fractions using ultrahigh resolution mass spectrometry has shown that three types of humic PAs were obtained with distinctively different chemical properties. The ethanol-soluble PAs (HMA) had the highest content of CHO aliphatic and alicyclic structures with the most extended series of $\mathrm{CH}_{2}$ homologues (Fig. 1), which might confer to the highest lipophilicity of this fraction. The acid soluble FA had the highest content of heteroatoms resulting in its hydrophilicity. The acid insoluble HA had the highest aromaticity index and contained more heteroatoms than HMA witnessing the higher acidity of HA. The hydrogen-donating properties were consistent with the above molecular compositions (Table 1). Hence, fractionation of the initial HS extract (HFA) was rather efficient in yielding humic PAs with substantially different hydrogendonating and lipophilic properties. Having humic PAs with these properties enabled us to study structure-anti-HIV activity relationships.

\section{Anti-HIV activities of the fractionated humic PAs}

While examining Table 2 for activity against HIV-1 $1_{\text {LAI.2 }}$, it was found that all three humic PAs have EC50 values lying between 0.04 and $6.7 \mu \mathrm{g} \mathrm{mL}^{-1}$. This made us conclude that all humic PAs displayed excellent anti-HIV properties which exceeded or were comparable to those reported for both sulfonated and carboxylated PAs. So, the corresponding EC50 values (in $\mu \mathrm{g} \mathrm{mL}^{-1}$ ) were, for dextran-sulphate (DS) against HIV-1 III-B $_{\text {and HIV-1 }}$ NL4-3, varied from 0.1 to $1.5 ;{ }^{21,39,64}$ for heparin against HIV- $1-0.5 ;{ }^{64}$ for cellulose sulfate against HIV- 1 in $\mathrm{CD}^{+}{ }^{+} \mathrm{T}$ cells $-10,{ }^{65}$ for polysterene sulfonates (PSSs) against HIV-1 in $\mathrm{CD}^{+}{ }^{+} \mathrm{T}$ cells - 11.6, ${ }^{65}$ for naphthalene sulfate polymers (condensation products of naphthalenesulfonic acid and formaldehyde) PIC 024-4 and PRO 2000-against HIV-1 strain 14aPre in PBMC cells $-12.8,{ }^{66}$ for PRO_2000 against HIV-1 in CD4 ${ }^{+}$T cells $-2.75,{ }^{65}$ for polycarboxylated celluloses against HIV-1 in CD4 LTR $\beta$-Gal cells: cellulose acetate phthalate (CAP) - 1.5, cellulose acetate trimellitate (CAT) - 5.4, hydroxypropylmethylcellulose phtalate (HPMCP) - 6.7, hydroxypropylmethylcellulose trimellitate (HPMCT) - 0.6, ${ }^{21}$ for PAMAM-based dendrimers modified with naphthalenesulfonic moieties (BR12923 and BR16195) against HIV-1 III-B $_{\text {in }}$ MT4-cells -0.1 and $0.3,{ }^{21}$ for a series of tetracarboxylate cosalane derivatives against HIV- $1_{\text {III-B }}$ in SEM-SS-cells $-6-13,{ }^{23}$ for maleic acid-containing copolymer, formed by polymerizing divinyl ether and maleic anhydride (DIVEMA), against HIV-1 $-8{ }^{6,67}$ and for a series of semirigid carboxylated copolymers (alt-Maleic-Stylbene (or Styrene) polymers) - between 0.1 and 2.27. ${ }^{24}$

For comparison, the $\mathrm{EC}_{50}$ values for the most efficient HMA reached in step 1 and step 2 of the EASY-HIT assay accounted for 0.038 and $0.044 \mu \mathrm{g} \mathrm{mL} \mathrm{L}^{-1}$, the best $\mathrm{EC}_{50}$ value for PBMC cells achieved for HMA $\left(0.98 \mu \mathrm{g} \mathrm{mL}^{-1}\right)$ lay on the bottom side of all the classes of sulphonated and carboxylated PAs reviewed above. Hence, the undertaken fractionation allowed us to substantially enhance the efficacy of the humic PAs studied. The most potent fraction was HMA, which exceeded or equaled the efficacy of synthetic polycarboxylates in all antiviral tests.

\section{Linking molecular compositions to activities of humic PAs}

Given that unlike synthetic polyelectrolytes, supramolecular ensembles of humic PAs may possess several molecular scaffolds contributing to the displayed anti-HIV activity, we have defined common and unique formulas present in the three humic PAs as described in our previous studies ${ }^{68}$ and related them to the corresponding type of activity as shown in Fig. 4. 


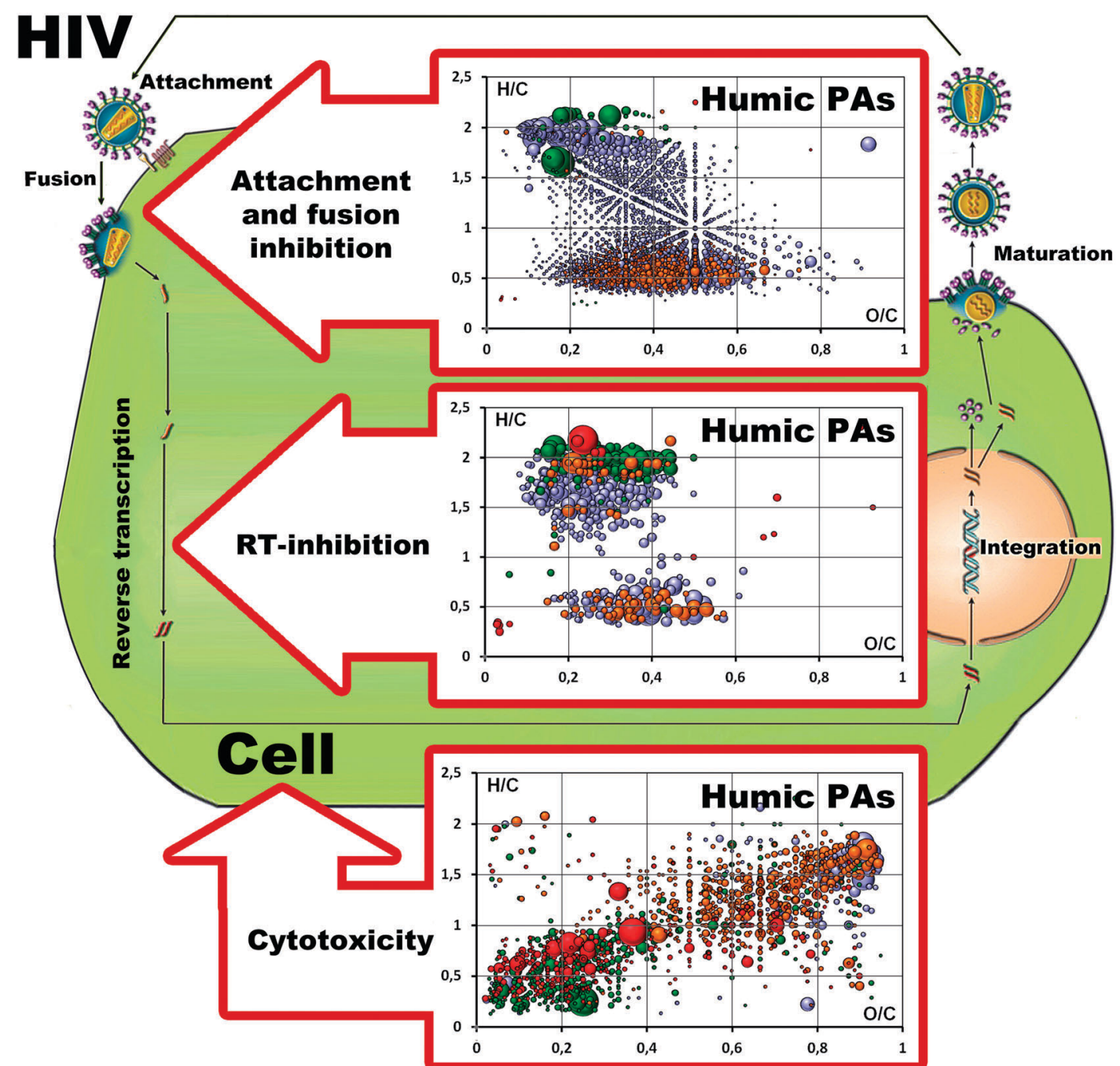

Fig. 4 Van Krevelen diagrams plotted for: the common molecular formulas of HA, HMA, and FA (upper row); the common molecular formulas of HA and HMA (middle row); and the unique molecular formulas of FA (absent in HA and HMA) (bottom row). The diagrams are placed in the context of the corresponding anti-HIV activity or cytotoxicity along the HIV-life cycle in the cell.

Upon conducting this analysis we paid particular attention to the common molecules present in all three fractions (HA, HMA and FA) (shown in the upper part of Fig. 4): we hypothesized that these compositions might be responsible for the attachment and fusion inhibitory activities, which were observed for all humic PAs under study.

It can be seen that molecules common to all three humic PAs occupied rather a large chemical space ranging from the aliphatic lipidic compartments with $\mathrm{H} / \mathrm{C}$ values as high as 2.0 to the condensed aromatic compartment with an $\mathrm{H} / \mathrm{C}$ value of 0.4 ; the corresponding $\mathrm{O} / \mathrm{C}$ values ranged from 0.15 to 0.7 . It might be concluded that this pool was represented by different molecular scaffolds carrying carboxylic functions (e.g. aromatic carboxylates, carboxyl-rich alicyclic moieties (CRAM), ${ }^{69}$ fatty acids, and hydrolyzable tannins) which allowed for the type of activity observed: they were capable of blocking virus adsorption to the surface of the host cell membrane $\left(\mathrm{CD}^{+}\right)$through electrostatic interactions with the V3 loop of the HIV-1 glycoprotein 120 (gp120) or the glycoprotein 41 (gp41) complex. This property is common to all polyanions including carboxylated and sulphonated/sulphated polymers regardless of the exact molecular formulas. Hence, all humic PAs can be seen as potent candidates for microbicide development aimed at the prevention of virus infection.

A further step was to define the common molecules which were present both in HA and HMA, but absent in FA: these molecules might contribute the most to the RT-inhibition activity. This type of activity was observed in HA and HMA, but it was not displayed by FA. The pool of these molecules is shown in the middle Van Krevelen diagram in Fig. 4. It is presented by two separate "islands": the first one lies in the range of "lipidic" and "peptidic" saturated compartments and is related to terpenoids with $\mathrm{H} / \mathrm{C}$ values in the range of 1.1-1.7 and $\mathrm{O} / \mathrm{C}$ values from 0.1 to 0.4 , to peptides with $\mathrm{H} / \mathrm{C}$ values ranging from 1.6 to 2 and $\mathrm{O} / \mathrm{C}$ values from 0.25 to 0.7 , whereas the second "island" includes condensed aromatic compartments (lignans, flavons, flavonols, coumarins, quinonic terpenoids, and others). ${ }^{45,70}$ The presence of similar lipophilic compartments 


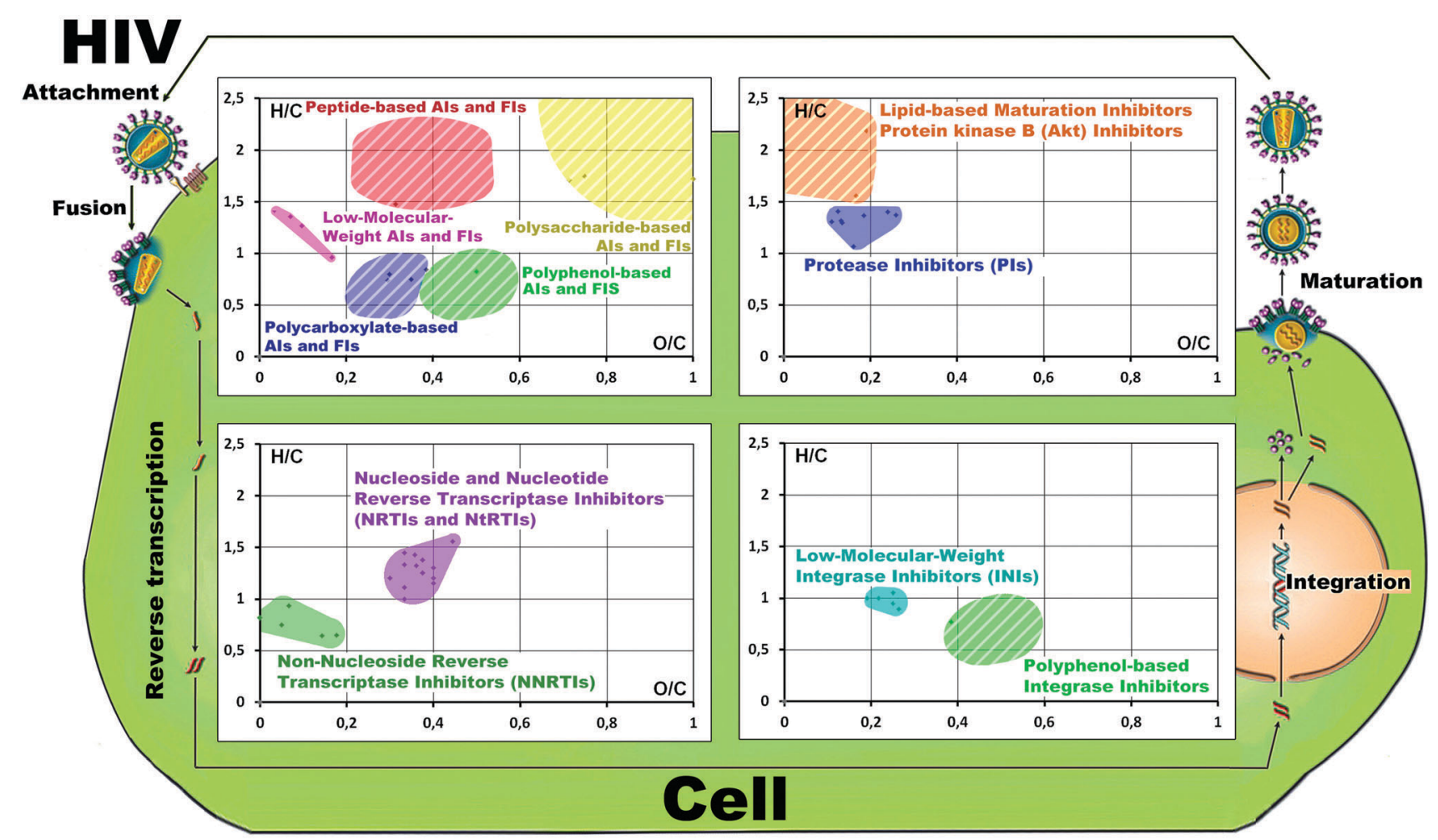

Fig. 5 Molecular space of four different classes of antiretroviral compounds plotted in the Van Krevelen diagrams positioned along the HIV-life cycle. A detailed description is given in the ESI. $\dagger$

might indicate the capability of HA and HMA for penetration into the cell interior. In our previous studies we have shown that the most hydrophobic HS from coal was accumulated in the bacterial cells. ${ }^{71}$ This is of particular importance given that both HMA and HA are enriched with common molecules located in the region of terpenoids, lignans, flavonoids, and other polyphenols with the reported RTI activities. ${ }^{56-62}$ According to the hypothesis of Bruccoleri, ${ }^{40}$ the quinonoid rich components of HSs might act as non-nucleoside reverse transcriptase inhibitors. This is also in line with multiple data on the high anti-HIV activity of the synthetic HS obtained by polymerization of quinones. ${ }^{37,38}$ It should also be noted that both HA and HMA had excellent safety profiles - cytotoxicity was not detected in the whole range of concentrations tested.

To explore the possible source for cytotoxicity which was seen for the high concentration of FA, we have defined the unique molecular compositions which were present in FA, but absent in HA and HMA (shown in the bottom Van Krevelen diagram in Fig. 4). It can be seen that FA showed very distinct molecular patterns enriched with sulfur-containing components (shown by green and red dots in Fig. 4). The high oxidation degree of these compartments might indicate the oxidized character of sulfur - the presence of sulphonic groups. These heteroatom rich compartments might be responsible for the much higher cytotoxicity of FA compared to HA and HMA.

To visualize the possible profile of the antiretroviral activity of HSs, we have plotted Van Krevelen diagrams for all known single-molecule antiretroviral drugs and polyanionic microbicides (shown in Fig. 5 and Fig. S7, ESI $\dagger$ ) and positioned them in the context of the life cycle of HIV. The corresponding calculations are given in Table S3 (ESI $\dagger$ ).

Of interest is that excellent clustering was observed for the molecular compositions of the drugs with a certain type of antiretroviral activity in the obtained VK diagrams. For example, common molecular compositions of HA and HMA strongly overlapped with the space occupied by carboxylated PAs and polyphenolic PAs. This shows interesting possibilities for using these data as a source of additional information analysis in search of active ingredients in the natural matrices.

\section{Conclusions}

The presented research has shown the excellent multimodal anti-HIV activities of the supramolecular assemblies of three types of humic PAs isolated from the sulphide balneological mud using traditional alkaline extraction followed by fractionation with regard to charge density and polarity. We could demonstrate that the most hydrophilic, strongly charged FA behaved as a typical anionic polymer and displayed excellent entry inhibition activity, whereas two more hydrophobic PAs - HA and HMA - displayed both entry and RT-inhibition activities. The latter was the most remarkable for aliphatic-enriched HMA. The anti-retroviral mapping of the molecular space of the humic PAs allowed us to suggest a substantial contribution of less-oxidized and least charged scaffolds related to lignans-, 
terpenoids, coumarins-, and flavonoids with high RT-inhibition activity to the molecular composition of HMA, whereas HA could be dominated with more oxidized and charged components of hydrolyzed tannins and other polyphenols, the RTI-activity of which has also been well documented. ${ }^{56-62}$ This interplay of different anti-HIV activities inherent to diverse structural scaffolds comprising supramolecular assemblies of natural humic PAs makes of particular importance the use of highresolution FTICR MS data for the generation of more meaningful structural descriptors, which can be used for SARs, as well as implies the use of more sophisticated separation techniques for refining the antiviral activities of humic PAs.

Hence, the obtained results might open a new direction in the supramolecular chemistry of natural complex matrices aimed at mapping their molecular space with regard to the types of antiretroviral activities. This will enable targeted isolation of molecular combinations with the required types of antiretroviral activities. From the drug-development perspective, this will force the application of high-tech molecular separation and high resolution characterization of the obtained combinations. The next steps in this direction could be realized using solid phase extraction and ultrahigh resolution high pressure liquid chromatography for fractionation of humic PAs. It can confer even higher antiretroviral activity to the humic-based microbicides. The broad-range antiviral activities along with extremely low toxicity and high selectivity indexes provide good perspectives for the development of the humic-based microbicides with polymodal anti-HIV activities.

\section{Experimental}

\section{Isolation and characterization of well-defined fractions of humic polyanions}

The source for the isolation of the HS fractions was lowmineralized silt sulfide muds of the Molochka Lake of the Samara region, Russia $\left(53^{\circ} 51^{\prime} 8^{\prime \prime} \mathrm{N} ; 51^{\circ} 37^{\prime} 28^{\prime \prime} \mathrm{E}\right)$. The lake is characterized by large peloid deposits formed as a result of accumulation of terrigenic silt and detritus of an autochthonous origin under the influence of sulfate waters and anaerobic microflora. The mud is rich in organic matter (up to $7 \%$ organic carbon), which is considered to be a source of its high biological activity. ${ }^{72}$ HSs were isolated using extraction with $0.5 \mathrm{M} \mathrm{NaOH}$ as described in ref. 73 and schematically shown in Fig. S1 (ESI $\dagger$ ). A portion of this extract was desalted using a cation exchanger and designated as HFA. Another portion was further fractionated into fulvic acid (FA), humic acid (HA), and hymatomelanic acid (HMA). In brief, the obtained alkali extract was acidified to $\mathrm{pH} 1 \mathrm{using} 50 \% \mathrm{H}_{2} \mathrm{SO}_{4}$. The precipitate of HA was centrifuged and treated with anhydrous ethanol at $45-48{ }^{\circ} \mathrm{C}$ using a Soxhlet extractor to isolate the HMA fraction. The supernatant was desalted and freeze-dried to isolate the FA fraction. All solutions of the HS fractions were sterilized using $0.45 \mu \mathrm{m}$ syringe-filters (Merck Millipore Ltd) and stored at $-20{ }^{\circ} \mathrm{C}$ until use.

Elemental compositions (CHNS) were found using a Vario EL analyzer (Germany). The ash content was determined manually using a combustion technique. The content of oxygen was calculated as a difference (in \% mass): $\mathrm{O}=100-(\mathrm{C}+\mathrm{H}+\mathrm{N}+\mathrm{S})$.

Lipophilicity was estimated using a reverse-phase liquid chromatographic (RPLC) system "MilliChrom-1" ("Econova", Russia) with a $6 \times 1 \mathrm{~cm}$ column packed with Octyl Sepharose CL-4B (Pharmacia, Uppsala, Sweden). The HS solutions were diluted $1: 1(\mathrm{v} / \mathrm{v})$ with $0.1 \mathrm{M}$ Tris-HCl buffer/4 $\mathrm{M}\left(\mathrm{NH}_{4}\right)_{2} \mathrm{SO}_{4}$ and injected into the column equilibrated with $0.05 \mathrm{M}$ Tris- $\mathrm{HCl}$ buffer $\left(\mathrm{pH} \mathrm{8.0)/2.0} \mathrm{M}\left(\mathrm{NH}_{4}\right)_{2} \mathrm{SO}_{4}\right.$. Elution of HS fractions was performed first with $0.05 \mathrm{M}$ Tris- $\mathrm{HCl}$ buffer at a negative concentration gradient of ammonium sulfate, and then with an increasing concentration of sodium dodecyl sulfate. The elution rate was $50 \mathrm{~mL} \mathrm{~h}^{-1}$. A UV-vis detector was used for registering HSs at the exit of the column $(280 \mathrm{~nm})$. The obtained elution profiles are shown in Fig. S2 (ESI $\dagger$ ).

The content of acidic groups was determined using potentiometric titrations. A weight of $50 \mathrm{mg}$ of the solid sample was dissolved in $20 \mathrm{~mL}$ of $0.1 \mathrm{M} \mathrm{NaOH}$, added with $2.5 \mathrm{~mL}$ of $1 \mathrm{M} \mathrm{KCl}$, and diluted to $25 \mathrm{~mL}$. Titrations were conducted at 20-22 ${ }^{\circ} \mathrm{C}$. Back titration was conducted using $0.1 \mathrm{M} \mathrm{HCl}$ (from pH 11.5 to 2.5), and direct titration - using 0.1 M NaOH from $\mathrm{pH} 2.5$ up to 11.5 .

Molecular compositions of the humic PAs used in this study were determined using a 12 Tesla SOLARIX FTICR mass spectrometer (Bruker Daltonics, Bremen, Germany) and electrospray ionization (ESI) in the negative mode. The samples were dissolved in water at a concentration of $2 \mathrm{~g} \mathrm{~L}^{-1}$ and diluted with methanol $(1: 1)$. The injections were performed using a microlitre pump at a flow rate of $120 \mu \mathrm{L} \mathrm{h} \mathrm{h}^{-1}$. Nitrogen was used for both sheath gas and curtain gas. A source heater temperature of $200{ }^{\circ} \mathrm{C}$ was maintained to ensure rapid solvent evaporation in the ionized droplets. Spectra were acquired with a time domain sampling rate of 4 megaword and a total of 500 scans were accumulated for each spectrum. Spectra were internally calibrated using an appropriate reference mass list. The data acquisitions as well as handling were performed using Data Analysis Software from Bruker (Bruker Daltonics, Bremen, Germany) and home-made programs. To translate exact molecular masses into molecular formulas, a linear Diophantine equation for a given mass and a given set of atoms (e.g. C, H, N, O, and S) was solved.

\section{Virus production}

HIV-1 stocks were produced using HEK-293T cells transfected with proviral plasmids and analyzed for infectivity, signal induction, the absence of cell toxicity and p24 quantity as described in the study of Kremb et al. ${ }^{55}$ The X4-tropic strain HIV $-1_{\text {LAI }}{ }^{74}$ was produced by transfection with the proviral plasmid pLAI.2 and the R5-tropic GFP reporter virus HIV-1 NL4-3 Gag-iGFP ${ }^{75,76}$ - with pBR-NL4-3 V92th014.12-IRES-eGFP.

\section{Cells and cell culture}

The LC5-CD4 cell line is a HeLa subline engineered for the cell-surface expression of CD4. ${ }^{55}$ The HIV-1 reporter cell line LC5-RIC contains a reporter gene for the Rev- and Tat-dependent expression of a red fluorescent protein. LC5-RIC-R5 cells were 
generated by the stable transduction of LC5-RIC cells with human CCR5 cDNA in the pMSCVPuro backbone. LC5-RIC, LC5-RIC-R5, and HEK293T (ATCC ${ }^{\circledR}$-Number CRL-11268) cells were cultured as described by Kremb et al. ${ }^{55}$ Human peripheral blood mononuclear cells (PBMCs) were isolated from buffy coats by Ficoll (Biochrom AG) gradient centrifugation. ${ }^{77}$ Cells were washed and treated with ammonium chloride potassium (ACK) buffer (Gibco) to remove residual platelets and erythrocytes, respectively. PBMCs were stored at $-80{ }^{\circ} \mathrm{C}$ in batches of $1 \times 10^{7}$ cells pooled from 4 donors in $1 \mathrm{~mL}$ of VLE-RPMI 1640 medium (Biochrom AG, Berlin) with 20\% FCS (Gibco) and 10\% DMSO (Sigma Aldrich). Primary human macrophages were isolated from PBMCs as described elsewhere. ${ }^{75}$

\section{Reference HIV-1 inhibitors}

AZT and RAL were purchased from Sigma-Aldrich. T-20, Fusion Inhibitor from Roche, was obtained through the NIH AIDS Research and Reference Reagent Program, Division of AIDS, NIAID, NIH.

\section{EASY-HIT-assay}

Assay for the inhibition of HIV-1 infection of LC5-RIC cells was conducted using the EASY-HIT protocol. ${ }^{55}$ The humic PAs were tested in serial dilutions $(1 / 2,1 / 4,1 / 8,1 / 16, \ldots)$. The liquated portions $(100 \mu \mathrm{L})$ were placed into each well of a 96 well plate and $20 \mu \mathrm{L}$ of HIV-1 $1_{\text {LAI. } 2}$ inoculum were added.

\section{MTT test}

Cell viability was assessed using an MTT test (MTT is 3-(4,5dimethylthiazol-2-yl)-2,5-diphenyltetrazoliumbromide). The protocol was used as proposed by Kremb et al. ${ }^{55}$ The details are described in the ESI. $\dagger$

\section{PBMC-based infection assay}

Human PBMCs were treated with a solution of Interleukin-2 (50 units per mL; RPMI) (Roche) for $72 \mathrm{~h}$ prior to HIV-1 infection. PBMCs were seeded into 96-well plates at a density of $5 \times 10^{5}$ per well. Further actions were the same as in the EASY-HIT protocol. ${ }^{55}$

\section{Time-of-addition assay}

Time-of-addition assays were performed using the EASY-HIT protocol in standard 96-well plates with some modifications. ${ }^{55}$ HIV-1 $1_{\text {LAI.2 }}$ was added to LC5-RIC-R5 cell cultures at the initial time point $(0 \mathrm{~s})$. The humic PAs were added to the cell cultures at different time points after the addition of the virus. At least 15 time points were evaluated for each compound in three replicates. The cultures were incubated with the virus for $48 \mathrm{~h}$.

\section{HIV-1-cell attachment assay}

HIV-1-cell attachment assays were performed with the HIV-1 NL4-3 Gag-iGFP reporter virus and LC5-RIC-R5 cells in the presence of the HIV-1 fusion inhibitor T-20 (50 nM). LC5-RIC-R5 cells $\left(2 \times 10^{5}\right)$ were seeded onto $24 \times 24 \mathrm{~mm}$ cover slips placed in 6-well plates. After 24 hours, the culture medium was replaced with the fresh medium containing inhibitor compounds (100 $\mu \mathrm{g} \mathrm{mL} \mathrm{m}^{-1}$, or $5 \mathrm{nM}$ Griffithsin reference compound) and virus inoculum (8.5 pg p24 per cell). After $4 \mathrm{~h}$ of incubation at $37{ }^{\circ} \mathrm{C}$, the cells were fixed in $2 \%$ paraformaldehyde (PFA) in PBS at room temperature for 10 minutes and treated with DAPI-staining solution for 5 minutes at room temperature for staining of cellular DNA. The cells were washed and coverslips were fixed onto glass-slides with Moviol and dried in the dark overnight. The obtained samples were analyzed using fluorescence microscopy (Nikon TiE equipped with a Perkin Elmer UltraView Vox System). The exposure times were as follows: GFP - $100 \mathrm{~ms}$, DAPI - various, and Brightfield - various. Counting of virus particles (GFP spots defined as all pixels within a radius of $1 \mu \mathrm{m}$ around the brightest spot, intensity threshold 755) was performed using Volocity 6.2.1-software (Perkin Elmer). DAPIpositive cells were counted manually.

\section{Reverse transcriptase assay}

Reverse transcriptase activity was determined using an EnzChek Reverse Transcriptase Assay Kit (Molecular Probes, Inc., USA) with a purified recombinant HIV reverse transcriptase (Roche Diagnostics $\mathrm{GmbH}$, Germany). Five microliters of the serially diluted humic PAs (initial concentration of $100 \mu \mathrm{g} \mathrm{mL} \mathrm{mL}^{-1}$ ) or $\lambda$ DNA standard, which were used to prepare a standard curve, were added to a reverse transcription reaction mixture containing HIV reverse transcriptase ( 3 units) and 350 base long poly(A) templates primed with oligo $\mathrm{d}(\mathrm{T})_{16}$ primers in a $25 \mu \mathrm{L}$ reaction volume in a 96-well plate and incubated at $25{ }^{\circ} \mathrm{C}$ for 60 minutes. The reaction was stopped by adding $2 \mu \mathrm{L}$ of $200 \mathrm{mM}$ EDTA to each well at $4{ }^{\circ} \mathrm{C}$. Then, the resulting long RNA-DNA heteroduplexes generated in each well were detected using a spectrofluorometer Tecan infinite M200. The quantitative measurements were conducted using the PicoGreen dsDNA quantitation reagent $(173 \mu \mathrm{L})$ provided in the kit. Fluorescence was measured using an excitation wavelength of $480 \mathrm{~nm}$ and an emission wavelength of $520 \mathrm{~nm}$.

\section{Statistical analysis}

$\mathrm{EC}_{50}$ and $\mathrm{CC}_{50}$ values were calculated using GraphPad Prism v.5.00 using the equation for sigmoidal dose-response with a variable slope. The therapeutic value of the drug was estimated using the selectivity index (SI), which is calculated as the ratio of $50 \%$ cytotoxic concentration $\left(\mathrm{CC}_{50}\right)$ to $50 \%$ effective concentration $\left(\mathrm{EC}_{50}\right)$. Statistical significances were determined using one-way Anova with the Bonferroni post hoc test $(p<0.0001)$.

\section{Acknowledgements}

The authors are thankful to the German Academic Exchange Service (DAAD) and International Humic Substances Society (IHSS) for the research fellowship allocated to Yury Zhernov for his stay at Helmholtz Zentrum München (Germany). This work was partially supported by the Russian Foundation for Basic Research (projects 16-03-01057 and 16-04-01753).

\section{References}

1 P. Zhan, C. Pannecouque, E. De Clercq and X. Liu, J. Med. Chem., 2016, 59(7), 2849-2878, DOI: 10.1021/ acs.jmedchem.5b00497. 
2 E. De Clercq, Rev. Med. Virol., 2009, 19, 287-299.

3 AIDSinfo, HIV Treatment - FDA-Approved HIV Medicines (Last updated 5/4/2015s last reviewed 5/4/2015), https:// aidsinfo.nih.gov/education-materials/fact-sheets/21/58/fdaapproved-hiv-medicines.

4 J. E. Gallant, P. Z. Gerondelis, M. A. Wainberg, N. S. Shulman, R. H. Haubrich, M. St Clair, E. R. Lanier, N. S. Hellmann and D. D. Richman, Antiviral Ther., 2003, 8, 489-506.

5 M. A. Wainberg, J. P. Sawyer, J. S. Montaner, R. L. Murphy, D. R. Kuritzkes and F. Raffi, Antiviral Ther., 2005, 10, 13-28.

6 H. Mitsuya, D. J. Looney, S. Kuno, R. Ueno, F. Wong-Staal and S. Broder, Science, 1988, 240, 646-649.

7 A. Leydet, C. Moullet, J. P. Roque, M. Witvrouw, C. Pannecouque, G. Andrei, R. Snoeck, J. Neyts, D. Schols and E. De Clercq, J. Med. Chem., 1998, 41, 4927-4932.

8 A. R. Neurath, N. Strick, Y.-Y. Li and A. K. Debnath, BMC Infect. Dis., 2001, 1, 17.

9 M. Baba, R. Pauwels, J. Balzarini, J. Arnout, J. Desmyter and E. De Clercq, Proc. Natl. Acad. Sci. U. S. A., 1988, 85, 6132-6136.

10 L. N. Callahan, M. Phelan, M. Mallinson and M. A. Norcross, J. Virol., 1991, 65, 1543-1550.

11 M. Moulard, H. Lortat-Jacob, I. Mondor, G. Roca, R. Wyatt, J. Sodroski, L. Zhao, W. Olson, P. D. Kwong and Q. J. Sattentau, J. Virol., 2000, 74, 1948-1960.

12 V. Pirrone, B. Wigdahl and F. C. Krebs, Antiviral Res., 2011, 90, 168-182.

13 L. Van Damme, R. Govinden and F. M. Mirembe, et al., N. Engl. J. Med., 2008, 359, 463-472.

14 J. Cohen, Science, 2008, 319, 1026-1027.

15 A. M. Micsenyi, C. Zony, R. A. Alvarez, N. D. Durham, B. K. Chen and M. E. Klotman, J. Infect. Dis., 2013, 208, 1756-1767.

16 D. Sepúlveda-Crespo, M. J. Serramía, A. M. Tager, V. Vrbanac, R. Gómez, F. J. De La Mata, J.-L. Jiménez and A. Muñoz-Fernández, Nanomedicine, 2015, 11, 1299-1308.

17 V. Pirrone, S. Passic, B. Wigdahl, R. F. Rando, M. Labib and F. C. Krebs, J. Biomed. Biotechnol., 2010, 2010, 1-11.

18 M. Cushman, P. Wang, S. H. Chang, C. Wild, E. De Clercq, D. Schols, M. E. Goldman and J. A. Bowen, J. Med. Chem., 1991, 34, 329-337.

19 A. Leydet, C. J. Segonds, C. Bouchitte, C. Moullet, B. Boyer, J.-P. Roque, M. Witvrouw, J. Este, R. Snoeck, G. Andrei and E. De Clercq, J. Med. Chem., 1997, 40, 350-356.

20 H. Kokubo, S. Obara, K. Minemura and T. Tanaka, Chem. Pharm. Bull., 1997, 45, 1350-1353.

21 R. F. Rando, S. Obara, M. C. Osterling, M. Mankowski, S. R. Miller, M. L. Ferguson, F. C. Krebs, B. Wigdahl, M. Labib and H. Kokubo, Antimicrob. Agents Chemother., 2006, 50(9), 3081-3089.

22 A. R. Neurath, N. Strick and Y.-Y. Li, BMC Infect. Dis., 2002, $2,27$.

23 K. C. Santhosh, G. C. Paul, E. De Clercq, C. Pannecouque, M. Witvrouw, T. L. Loftus, J. A. Turpin, R. W. Buckheit, Jr. and M. Cushman, J. Med. Chem., 2001, 44, 703-714.
24 A. M. Savage, Y. Li, L. E. Matolyak, G. F. Doncel, S. R. Turner and R. D. Gandour, J. Med. Chem., 2014, 57(15), 6354-6363.

25 W. Fang, Y. Cai, X. Chen, R. Su, T. Chen, N. Xia, L. Li, Q. Yang, J. Han and S. Han, Bioorg. Med. Chem. Lett., 2009, 19, 1903-1907.

26 D. Tyssen, S. A. Henderson, A. Johnson, J. Sterjovski, K. Moore, J. La, M. Zanin, S. Sonza, P. Karellas, M. P. Giannis, G. Krippner, S. Wesselingh, T. McCarthy, P. R. Gorry, P. A. Ramsland, R. Cone, J. R. A. Paull, G. R. Lewis and G. Tachedjian, PLoS One, 2010, 5(8), e12309, DOI: 10.1371/journal.pone.0012309.

27 Y. Li, M. Mao, L. E. Matolyak and S. R. Turner, ACS Macro Lett., 2012, 1, 257-260.

28 C. B. Buck, C. D. Thompson, J. N. Roberts, M. Müller, D. R. Lowy and J. T. Schiller, PLoS Pathog., 2006, 2, e69.

29 R. A. Anderson, K. A. Feathergill, X.-H. Diao, M. Cooper, R. Kirkpatrick, P. Spear, D. P. Waller, C. Chany, G. F. Doncel, B. Herold and L. J. D. Zaneveld, J. Androl., 2000, 21, 862-875.

30 A. Nebbioso and A. Piccolo, Biomacromolecules, 2011, 12, 1187-1199.

31 F. J. Stevenson, Humus Chemistry: Genesis, Composition, Reactions, John Wiley \& Sons, New York, 2nd edn, 1994.

32 J. Schneider, R. Weis, C. Manner, B. Kary, A. Werner, B. J. Seubert and U. N. Riede, J. Virol., 1996, 218(2), 389-395.

33 G. K. Joone, J. Dekker and C. E. Van Rensburg, Z. Naturforsch., C: J. Biosci., 2003, 58(3-4), 263-267.

34 C. E. Van Rensburg, J. Dekkee, R. Weis, T. L. Smith, E. Janse van Rensburg and J. Schneider, Chemotherapy, 2002, 48(3), 138-143.

35 Yu. V. Zhernov, Proc. Natl. Acad. Sci. U. S. A., 2011, 1(8), 1996-1998.

36 F. J. Lu, S. N. Tseng, M. L. Li and S. R. Shih, Arch. Virol., 2002, 147(2), 273-284.

37 R. Kloecking, B. Helbig, G. Schotz, M. Schacke and P. Wultzer, Antiviral Chem. Chemother., 2002, 13(4), 241-249.

38 R. Kloecking and M. Sproessig, Experientia, 1972, 28, 607-608.

39 M. Baba, R. Snoek, R. Pauwels and E. De Clercq, Antimicrob. Agents Chemother., 1988, 32, 1742-1745.

40 A. Bruccoleri, AIDS Res. Hum. Retroviruses, 2013, 29(1), 4-12. 41 A. G. Marshall, C. L. Hendrickson and G. S. Jackson, Mass Spectrom. Rev., 1998, 17, 1-35.

42 N. Hertkorn, C. Ruecker, M. Meringer, R. Gugisch, M. Frommberger, E. M. Perdue, M. Witt and P. SchmittKopplin, Anal. Bioanal. Chem., 2007, 389, 1311-1327.

43 N. Hertkorn, M. Harir, B. Koch, B. Michalke and P. SchmittKopplin, Biogeosciences, 2013, 10, 1583-1624.

44 A. C. Stenson, A. G. Marshall and W. T. Cooper, Anal. Chem., 2003, 75, 1275-1284.

45 W. C. Hockaday, J. M. Purcell, A. G. Marshall, J. A. Baldock and P. G. Hatcher, Limnol. Oceanogr.: Methods, 2009, 7, 81-95.

46 A. Y. Zherebker, D. Airapetyan, A. I. Konstantinov, Y. I. Kostyukevich, A. S. Kononikhin, I. A. Popov, K. V. Zaitsev, E. N. Nikolaev and I. V. Perminova, Analyst, 2015, 140, 4708-4719. 
47 I. Schepetkin, A. Khlebnikov and B. S. Kwon, Drug Dev. Res., 2002, 57, 40-159.

48 M. A. Mirza, S. P. Agarwal, A. Rahman, A. Rauf, N. Ahmad, A. Alam and Z. Iqbal, Drug Dev. Ind. Pharm., 2011, 37(3), 310-319.

49 J. A. Rice and P. A. MacCarthy, Environ. Sci. Technol., 1990, 24, 1875-1877.

50 S. J. Driver and E. M. Perdue, Environ. Eng. Sci., 2015, 32(1), 66-70.

51 J. O. Grimalt, B. Hermosín, Y. G. Inmaculada and C. SaizJiménez, Sci. Total Environ., 1989, 81, 421-428.

52 C. Saiz-Jimenez and J. W. De Leeuw, J. Anal. Appl. Pyrolysis, 1986, 9(2), 99-119.

53 S. Kim, R. W. Kramer and P. G. Hatcher, Anal. Chem., 2003, 75, 5336-5344.

54 P. Sainvitu, K. Nott, G. Richard, C. Blecker, C. Jérôme, J.-P. Wathelet, M. Paquot and M. Deleu, Biotechnol., Agron., Soc. Environ., 2012, 16(1), 115-124.

55 S. Kremb, M. Helfer, W. Heller, D. Hoffmann, H. Wolff, A. Kleinschmidt, S. Cepok, B. Hemmer, J. Durner and R. Brack-Werner, Antimicrob. Agents Chemother., 2010, 54, 5257-5268.

56 J. M. Kilby, S. Hopkins, T. M. Venetta, B. Di Massimo, G. A. Cloud, J. Y. Lee, L. Alldredge, E. Hunter, D. Lambert, D. Bolognesi, T. Matthews, M. R. Johnson, M. A. Nowak, G. M. Shaw and M. S. Saag, Nat. Med., 1998, 4, 1302-1307.

57 Y.-S. Han, W.-L. Xiao, H. Xu, V. G. Kramer, Y. Quan, T. Mesplede, M. Oliveira, S. P. Colby-Germinario, H.-D. Sun and M. A. Wainber, Antiviral Chem. Chemother., 2015, 24(1), 28-38.

58 M. Chen, N. Kilgore, K.-H. Lee and D.-F. Chen, J. Nat. Prod., 2006, 69, 1697-1701.

59 W. R. Cunha, M. L. A. Silva, R. C. S. Veneziani, S. R. Ambrósio and J. K. Bastos, in Phytochemicals - A Global Perspective of Their Role in Nutrition and Health, ed. V. Rao, 2012, ISBN: 978-953-51-0296-0.

60 K. Andrae-Marobela, F. W. Ghislain, H. Okatch and R. R. T. Majinda, Curr. Drug Metab., 2013, 14, 392-413.

61 J. M. Landete, J. Food Res., 2011, 44, 1150-1160.

62 L.-T. Lin, T.-Y. Chen, C.-Y. Chung, R. S. Noyce, T. B. Grindley, C. McCormick, T.-C. Lin, G.-H. Wang, C.-C. Lin and C. D. Richardson, J. Virol., 2011, 85(9), 4386-4398.
63 I. V. Perminova, A. Gaspar, P. Schmitt-Kopplin, N. A. Kulikova, A. I. Konstantinov, N. Hertkorn and K. Hatfield, in BiophysicoChemical Processes Involving Natural Nonliving Organic Matter in Environmental Systems, ed. N. Senesi and B. Xing, IUPAC Book Series, Wiley, 2009, ch. 13, pp. 487-538.

64 E. O. Baranova, N. S. Shastina and V. I. Shvets, Russ. J. Bioorg. Chem., 2011, 37(5), 527-542.

65 I. A. Scordi-Bello, A. Mosoian, C. He, Y. Chen, Y. Cheng, G. A. Jarvis, M. J. Keller, K. Hogarty, D. P. Waller, A. T. Profy, B. C. Herold and M. E. Klotman, Antimicrob. Agents Chemother., 2005, 49, 3607-3615.

66 M. Luescher-Mattli, Antiviral Chem. Chemother., 2000, 11(4), 249-259.

67 A. Serbin, E. Karaseva, V. Tsvetkov, O. Alikhanova and I. Rodionov, Macromol. Symp., 2010, 296, 466-477.

68 I. V. Perminova, I. V. Dubinenkov, A. S. Kononikhin, A. I. Konstantinov, A. Ya. Zherebker, M. A. Andzhushev, V. A. Lebedev, E. Bulygina, R. M. Holmes, Yu. I. Kostyukevich, I. A. Popov and E. N. Nikolaev, Environ. Sci. Technol., 2014, 48(13), 7461-7468.

69 N. Hertkorn, R. Benner, M. Frommberger, P. Schmitt-Kopplin, M. Witt, K. Kaiser, A. Kettrup and J. I. Hedges, Geochim. Cosmochim. Acta, 2006, 70, 2990-3010.

70 E. Kujawinski and M. Behn, Anal. Chem., 2006, 78, 4363-4373. 71 N. A. Kulikova, I. V. Perminova, G. A. Badun, M. G. Chernysheva, O. V. Koroleva and E. A. Tsvetkova, Appl. Environ. Microbiol., 2010, 76(18), 6223-6230.

72 A. Jankowski, B. Nienartowicz, B. Polanska and A. LewandowiczUszynska, Arch. Immunol. Ther. Exp., 1993, 41(1), 95-97.

73 A. I. Agapov and N. P. Avvakumova, Patent RU 2028149, 1999.

74 K. Peden, M. Emerman and L. Montagnier, J. Virol., 1991, 185, 661-672.

75 H. Koppensteiner, C. Banning, C. Schneider, H. Hohenberg and M. Schindler, J. Virol., 2012, 86, 2826-2836, DOI: 10.1128/jvi.05915-11.

76 W. Huebner, P. Chen, A. Del Portillo, Y. Liu, R. E. Gordon and B. K. Chen, J. Virol., 2007, 81, 12596-12607, DOI: 10.1128/jvi.01088-07.

77 I. J. Fuss, M. E. Kanof, P. D. Smith and H. Zola, Current Protocols in Immunology, 2009, 7.11-7.18, DOI: 10.1002/ 0471142735.im0701s85. 